\title{
A SCIENTOMETRIC STUDY OF SCOPUS DATABASE - VETERINARY PUBLICATIONS FROM TAMIL NADU VETERINARY AND ANIMAL SCIENCES UNIVERSITY, CHENNAI
}

\author{
L. Rajendran $1 \rrbracket$ (iD
}

${ }^{1}$ Assistant Librarian, Department of Library Science, Madras Veterinary College, Tamil Nadu Veterinary and Animal Sciences University, Chennai, Tamil Nadu, India.

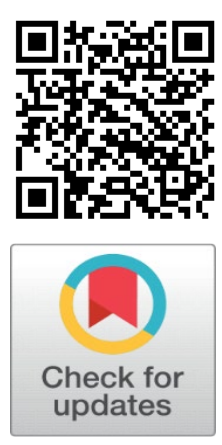

Received 5 November 2021

Accepted 15 December 2021

Published 31 December 2021

CorrespondingAuthor

L. Rajendran,rajendranlak@yahoo.com DOI

10.29121/granthaalayah.v9.i12.2021 .4442

Funding: This research received no specific grant from any funding agency in the public, commercial, or not-for-profit sectors.

Copyright: (C) 2021 The Author(s). This is an open access article distributed under the terms of the Creative Commons Attribution License, which permits unrestricted use, distribution, and reproduction in any medium, provided the original author and source are credited.

\section{ABSTRACT}

A Scientometric analysis of 2333 Veterinary research articles published in Scopus database has been carried out every year. The individual author's veterinary publication contributed $204(7.67 \%)$ research documents to the research output. 179 publications on veterinary analysis were published with the help of Indian experts between 1986 and 2020 , with a total of 179 papers published in 2011. The Indian Veterinary Journal, with 1280 papers $(54.86 \%)$, was the most requested journal, followed by the Indian Journal of Animal Sciences, with 369 papers (15.81\%). In the citation distribution, the year 2019 contributed citation has a high rate of $140(5.07 \%)$ referenced in the referred articles. In the distribution of published documents in sponsor research, the Indian Council of Agricultural Research has contributed 29 publications (1.24\%) articles. According to the survey, India has 2283 publications $(87.85 \%)$ of the global Veterinary Science research output out of 10 countries.

Keywords: Scientometrics, Scopus Database, Veterinary, TANUVAS, Tamil Nadu

\section{INTRODUCTION}

The seed for the founding and growth of TANUVAS was planted in 1876, when the Madras Veterinary College opened as an Agricultural School in Chennai, offering diploma and certificate courses in veterinary and animal sciences. The institute became a college in 1903 (01.10.1903), when it opened its doors at Dobbin Hall in Chennai and accepted 20 students for a three-year diploma programme known as the GMVC (Graduate of Madras Veterinary College). The Directorate of Veterinary Education and Research was established in 1969. In 1974, the institution was academically associated with Tamil Nadu Agricultural University (TNAU), and in 1976, it was designated as a constituent unit of TNAU. At 1985, a second veterinary college was established in Namakkal to meet the growing demand for veterinary education and research. The government of Tamil Nadu founded Asia's first veterinary and animal sciences university on September 20,1989, with its headquarters in Chennai. The university is known as Tamil Nadu Veterinary and Animal Sciences University (popularly abbreviated as TANUVAS) and employs around 627 people. TANUVAS is actively involved in research projects that are financed by national and international organisations, as well as the Tamil Nadu government. The Directorate of Research is responsible for the strategic planning of research programmes, the establishment of links with research organisations at the national and international levels, research monitoring via internal and external mechanisms, and the publication of more research contributions in Scopus journals by 
TANUVAS staff members.

\section{SOURCE}

Scopus is the most important abstract and citation database of peer-reviewed literature - scientific journals, books and convention lawsuits. Worldwide, Scopus is utilized by more than three thousand academic, authorities and company institutions and is the primary records supply that supports the Research Intelligence portfolio.

\section{REVIEW OF RELEVANT LITERATURE}

Scopus is the largest abstract and citation database of peer-reviewed literature - scientific journals, books and conference proceedings. Worldwide, Scopus is used by more than 3,000 academic, government and corporate institutions and is the main data source that supports the Research Intelligence portfolio.

Dalia El Khaled et al., (2018) have anatomized this work describes the global operations of dielectric and bio-impedance measures ways in colourful fields. Dielectric and bio-impedance spectroscopy are major non-damaging dimension systems with high-quality eventuality inside the era discipline. All outcomes produced by the Scopus database were used because the core of the take a look at in hand, with exceptional particulars from journals, papers and convention lawsuits being taken into consideration. The results of this evaluation show that the hobby in electrical parcels has risen inside the final times due to the advanced technological measures supplied on the clinical role. Results display that bioimpedance studies are hugely greater latest compared to dielectric studies, and are more directed toward clinical purposes whilst dielectric spectroscopy specializes in bodily elements, and is used substantially in engineering and cloth information. It may be stated that bio-impedance and dielectric spectroscopy are being decreasingly applied and that they have the ability to consolidate and decorate exploration disquisition.

Tripathi and Garg (2016) made the paper analyses publication output of India on cereal plants as contemplated by means of its coverage in Scopus worldwide database at some stage in 1965-2010 in gaps of five years. Analysis shows that highest wide variety of papers (40\%) become posted on rice, observed through wheat (29\%). Agricultural universities and establishments under the aegis of Indian Council of Agricultural Research (ICAR) had been maximum effective. A large range of papers had been published in journals originating from the advanced countries with low effect thing. The maximum quantity of papers was published in Indian Journal of Agricultural Sciences, followed by way of Indian Journal of Agronomy. Indian Agricultural Research Institute, New Delhi crowned the list the various prolific establishments observed through Punjab Agricultural University, Ludhiana. The primary research changed into targeted on 'genetics and plant breeding' accompanied by using 'agronomic factors'. The authorship sample well-known shows that co-authored papers accounted for $94 \%$ of total output. Most of the prolific authors had been affiliated to Indian Agricultural Research Institute, New Delhi.

Zoltan Krajcsak (2021) clarified the reason of this observe is to give a new scientometric model for measuring character clinical performance in Scopus article publications inside the subject of Business, Management, and Accounting (BMA). With the assist of this model, the examiner also compares the book overall performance of the pinnacle 50 researchers consistent with SciVal within the area of BMA, in every of the Central European V4 countries (Czech Republic; Hungary; 
Poland; Slovakia). To examine the scientific excellence of a complete of top 2 hundred researchers within the nations studied, we accrued and analyzed the statistics of a total of 1844 in part redundant and a complete of 1492 cleansed BMA guides. In the scope of the examiner, we decided the exceptional of the journals the usage of SCImago, the individual contributions to the magazine articles, and the number of citations the use of Scopus statistics. A comparison of individual overall performance, as shown with the aid of published journal articles, can be made based on the qualities of the journals, the willpower of the aggregated co-authorship ratios, and the variety of citations obtained. The performance of BMA researchers in Hungary lags behind the average of V4s in terms of amount, but in phrases of highquality it reaches this average. As for BMA magazine articles, the common wide variety of co-authors is between two and 3; regarding Q4 to Q2 publications, this range commonly will increase. In fact, inside the case of these $Q$ journals multiple co-authorship results in better citations, however it isn't the case concerning Q1 journals.

Mukherjee Bhaskar (2013) defined about the paper offers the bibliometric characteristics along with authorship pattern, citations obtained and relative normal performance of Prof. Lalji Singh an eminent Indian scientist inside the location of genome assessment, DNA finger printing, and so forth..They have an examine is based totally on the booklet data indexed in Web of Science and Scopus. Results display those 222 precise articles had been listed inside the databases with an average of 7-eight articles in step with 365 days. Of the 222 articles most effective 18 articles seemed in Indian journals. Most of the articles have been posted while he served at Centre for Cellular and Molecular Biology, Hyderabad at some point of 1987-2011. Authorship sample of Prof. Singh shows that he is serving as a pacesetter of his studies term and $\mathrm{K}$ Thangaraj is the man scientist with whom he wrote most. Almost all his articles seem in excessive-impact journals. The h-index of Prof. Singh is 30 in each the databases. He has obtained fellowships of all important national technological expertise academies as also 1/3 global academy. They have an examine concludes with a commentary that Prof. Singh can be a 'function model' for extra youthful research to conform with.

Hilary I Okagbue et al. (2020) discovered a preceding look at (https://doi.Org/10.1007/s11192-020-03457-x) determined a discrepancy between Elsevier's CiteScore and Clarivate Analytics' Journal Impact Factor (JIF) in library and information technology (LIS) journals. One opportunity to provide an explanation for this discrepancy can also lie inside the quantity and sort of documents used to calculate these magazine-based totally metrics. Using the top quartile of Scopus-indexed journals from 2011 to 2018, we assessed the range of files for each journal and year that were listed in Scopus and in Web of Science (WoS) in six fields of observe: LIS, discrete arithmetic and combinatory (DMC), remedy: epidemiology (ME), agriculture and organic sciences (ABS), social technological know-how: demography (SSD), and environmental engineering (EE). The wide variety of files in WoS turned into better than the ones indexed in Scopus for 4 fields of study: LIS, ME, SSD and EE, with a distinction of 1653, 3931, 635 and 197 files, respectively. For DMC and ABS, Scopus listed greater documents than WoS for the identical years and journals, the differential being 7 and 1284, respectively. The extra indexing of files in WoS than in Scopus in 4 fields of observe can also give an explanation for why the JIF of top-ranking LIS journals is one-of-a-kind than their Cite Score. To verify this possibility, one class (DMC) changed into examined in element. Of the sixteen DMC journals tested, $91.1 \%$ had been articles, whilst 8. Nine $\%$ of missing files were corrections, an erratum, an editorial, an summary document and in press articles. There had been no tremendous variations among 
the citation styles of the lacking DMC journals' documents in Scopus and WoS. Citations to missing files may additionally impact the Cite Score and JIF and have to thus be well listed.

Mohammadamin Erfanmanesh (2017) described through the years, the variety of journals indexed in Scopus has extended, although it varies substantially between nations. The increasing share of international journals of a rustic provides new venues for papers from that United States of America to be seen through other researchers global. In this work, we compare the relationship of a country's medical overall performance or e-book fulfilment with both its journals' quantity and fine. The specific objective of the take a look at is to pick out the connection among the USA's booklet success and the amount and fine of those use's journals listed in Scopus during 2005-2014. The e-book success of 102 individual countries, measured by their scientific productiveness, impact and collaboration indicators, the quantity of USA's Scopus-indexed journals in 2014 (a complete of 22,581 journals) as well as the quantity of its journals have been investigated. Scopus-listed journals are predominantly from Western Europe (48.9\%) and North America $(27.7 \%)$, with the USA and the United Kingdom dominate with a complete fifty $1 \%$. The contribution from the peripheral countries is relatively small; however there are a great number of contributions from the South-East Asian countries. Estonia is the quickest developing United States of America in phrases of having indexed journals in Scopus, following via Iran and Malaysia. Among the studied indices, it become located that publication success (overall guides and overall citations) of 102 countries is strongly correlated with quantity (number of listed journals and number of documents posted in listed journals) and exceptional (citations per paper, SJR, h-index, Cite Score and SNIP) indicators of use's journals. We can conclude that the medical productivity of a rustic relies critically at the variety of journals indexed from that use in citation databases. They have a look at presents a context with which the relative fulfilment of publications can be assessed, yielding new insights into the clinical impact of individual countries and the performance of journals that they published.

Kot and Grabara (2017) diagnosed there are some scientometrics and bibliometric analyzes inside the literature studied the control publication however there is lack of multidimensional quantitative analyzes related to guides especially management discipline. The paper purpose is to research the management guides in line with disciplines based totally on the 9 selected Eastern European journals' contents. The paper affects factors on the management area identity and based totally on it, it was determined that published articles are focusing in four management disciplines: "Corporate finance management; Knowledge and statistics control; Public management and NGOs and Strategic management". Most of studied journals publishing pastime are rather in diverse control disciplines not focused particularly regions.

\section{OBJECTIVES OF THE STUDY}

This study's main goal is to examine the findings of Scopus database veterinary journals published between 1986 and 2020. The study focuses in great detail on the following goals:

- To produce a Scopus Database year-by-year map of veterinary journal publications.

- The goal of this study was to look at the most productive authors in the Scopus database.

- To determine the distribution of publications by author. 
- To determine the distribution of citations

- Researching the most popular publication format

- To find out what the most popular terms are.

- The top ten veterinary journals with the most research publications will be examined using Scopus analysis.

- To determine how the publications of the countries are allocated by rank.

- The linguistic distribution of veterinary papers was determined using Scopus analysis.

\section{SCOPE AND METHODOLOGY}

The data was acquired by searching a database of veterinary articles publish ed in Scopus journals for the word identified by the author's hindex for the thirty-four years (1986-2020).

\section{LIMITATIONS}

- Since the publication was identified in a veterinary journal, it has been found in the Scopus journals database of citations.

- The scope of this research is limited to research papers published between 1986 and 2020.

\section{RESULT AND DISCUSSION}

To find out the Indian Veterinary authors at Tamil Nadu Veterinary Animal Sciences University, the data was reviewed and presented using a number of statistical approaches, including tables, from the Scopus database.

\subsection{YEARLY SHARING OF VETERINARY PUBLICATIONS IN SCOPUS-INDEX}

Table 1 shows the year-by-year sharing of publications in the Scopus database that are protected. The table summarizes the findings of the research. From the table, it is clear that between 1986 and 2020, a total of 2333 articles were published on a global scale, with an average publication rate of 68.62 articles each year. The number of articles published in veterinary journals reached an all-time high in 2011, with 179 (7.67\%).

\begin{tabular}{|ccccc}
\hline \multicolumn{4}{c}{ Table 1 Year Wise Publications of Veterinary journals in Scopus } \\
\hline Year & No. of Articles & Percentage & Cumulative & Percentage \\
\hline 1986 & 2 & 0.08 & 2 & 0.08 \\
\hline 1987 & 1 & 0.04 & 3 & 0.12 \\
\hline 1988 & 2 & 0.08 & 5 & 0.20 \\
\hline 1990 & 2 & 0.08 & 7 & 0.28 \\
\hline 1991 & 6 & 0.26 & 13 & 0.54 \\
\hline 1992 & 2 & 0.08 & 15 & 0.62 \\
\hline 1993 & 5 & 0.21 & 20 & 0.83 \\
\hline 1994 & 4 & 0.17 & 24 & 1.34 \\
\hline
\end{tabular}




\begin{tabular}{|ccccc}
\hline 1995 & 8 & 0.34 & 32 & 1.68 \\
\hline 1996 & 54 & 2.31 & 86 & 3.99 \\
1997 & 65 & 2.79 & 151 & 6.78 \\
\hline 1998 & 87 & 3.73 & 238 & 10.51 \\
\hline 1999 & 60 & 2.57 & 298 & 13.08 \\
\hline 2000 & 74 & 3.17 & 372 & 16.25 \\
\hline 2001 & 66 & 2.83 & 438 & 19.08 \\
\hline 2002 & 54 & 2.31 & 492 & 21.39 \\
\hline 2003 & 86 & 3.69 & 578 & 25.08 \\
\hline 2004 & 77 & 3.30 & 655 & 28.38 \\
\hline 2005 & 60 & 2.57 & 715 & 30.95 \\
\hline 2006 & 87 & 3.72 & 802 & 34.67 \\
\hline 2007 & 117 & 5.01 & 919 & 39.68 \\
\hline 2008 & 107 & 4.59 & 1026 & 44.27 \\
\hline 2009 & 72 & 3.08 & 1098 & 47.35 \\
\hline 2010 & 93 & 3.99 & 1191 & 51.34 \\
\hline 2011 & 179 & 7.67 & 1370 & 59.01 \\
\hline 2012 & 115 & 4.92 & 1485 & 63.93 \\
\hline 2013 & 81 & 3.47 & 1566 & 67.4 \\
\hline 2014 & 120 & 5.14 & 1686 & 72.54 \\
\hline 2015 & 111 & 4.76 & 1797 & 77.30 \\
\hline 2016 & 105 & 4.50 & 1902 & 81.8 \\
\hline 2017 & 144 & 6.17 & 2046 & 87.97 \\
\hline 2018 & 104 & 4.46 & 2150 & 92.43 \\
\hline 2019 & 122 & 5.23 & 2272 & 97.66 \\
\hline 2020 & 61 & 2.61 & 2333 & 100 \\
\hline $0 t a l$ & 2333 & 100 & & \\
\hline & & & & \\
\hline
\end{tabular}

\subsubsection{MOST PRODUCTIVE AUTHORS}

Balachandran $\mathrm{C}$ is the most highly ranked author in the Scopus analysis, with 204 publications (11.5\%), followed by Kumanan K with 123 papers (6.95\%). Table 2 shows that among the top ten most productive authors in the third Veterinary analysis, Vairamuthu S produced 89 papers (5.03\%), Muralimanohar B provided 77 papers (4.35\%), and Sivakumar T contributed the same number of papers.

\begin{tabular}{|c|c|c|c|}
\hline Sl. No. & Name of Author & Number of Paper & Percentage \\
\hline 1 & Balachandran C & 204 & 11.5 \\
\hline 2 & Kumanan K & 123 & 6.95 \\
\hline 3 & Vairamuthu S & 89 & 5.03 \\
\hline 4 & Muralimanohar B & 77 & 4.35 \\
\hline 5 & Sivakumar T & 77 & 4.35 \\
\hline 6 & Pazhanivel N & 68 & 3.85 \\
\hline 7 & Vijayarani K & 67 & 3.79 \\
\hline
\end{tabular}




\begin{tabular}{cccc}
\hline 8 & Nachimuthu K & 62 & 3.51 \\
9 & Jayathangaraj M C & 61 & 3.45 \\
10 & Roy P & 60 & 3.39
\end{tabular}

\subsubsection{AUTHOR WISE DISTRIBUTION OF PAPERS}

Table 3 depicts the authorship patterns by year, with 160 authors out of 4228 documents. In terms of number of authors, 1-25 produced 105 numbers of authors who published articles between 1986 and 2020. Only two documents were produced from a minimum range of publications covering more than 101 areas. 2016 is the year with the most double-authored contributions, at eight. With 11 written contributions apiece, the years 2017, 2018, and 2020 have the most three, four, and five written contributions. The year 2020 had the most entries, with thirteen from more than five authors.

\begin{tabular}{|cccc|}
\hline \multicolumn{4}{|c}{ Table 3 Distribution of Range of Authors } \\
\hline Sl. No. & Range of Authors & Number of Author & Percentage \\
\hline 1 & $1-25$ & 105 & 65.6 \\
\hline 2 & $26-50$ & 39 & 24.3 \\
\hline 3 & $51-75$ & 11 & 6.87 \\
\hline 4 & $76-100$ & 3 & 1.87 \\
\hline 5 & More than 101 & 2 & 1.25 \\
\hline
\end{tabular}

\subsubsection{DISTRIBUTION OF CITATIONS}

Between 1986 and 2020, 121 citations with a total contribution of 2333 were published, as shown in Table 4. The selection of the last five years has quoted the most articles out of the 34 years. Out of five years, there were 315 citations (13.65\%). The lowest number of citations was 104 in 2016, with 4.51 percent of other authors.

\begin{tabular}{|cccc|}
\hline \multicolumn{4}{|c}{ Table 4 Number and Percentage of Citations in Scopus } \\
\hline Sl. No. & Year & Number of Citations & Percentage \\
\hline 1 & 2020 & 121 & 5.24 \\
\hline 2 & 2019 & 140 & 6.07 \\
\hline 3 & 2018 & 105 & 4.55 \\
\hline 4 & 2017 & 315 & 13.65 \\
\hline 5 & 2016 & 104 & 4.51 \\
\hline
\end{tabular}

\subsubsection{LEADING FORMAT OF PUBLICATION}

The study finds that journal articles, with 2205 papers (94.5\%), are the most common source of publications covered by Scopus database for the specialty of Veterinary research, followed by reviews with 50 pieces $(2.14 \%)$. Short Survey is in third place with $28(1.20 \%)$, while Note and Conference Paper are in fourth and fifth positions, respectively, with $21(0.90 \%)$ and $18(0.77 \%)$. Table 5 lists the top nine different types of publications.

\begin{tabular}{|cccc|}
\hline \multicolumn{4}{|c}{ Table $\mathbf{5}$ Leading format of Publication } \\
\hline Sl. No. & Kinds of Document & No. Of Papers & Percentage \\
\hline 1 & Article & 2205 & 94.5 \\
\hline 2 & Review & 50 & 2.14 \\
\hline
\end{tabular}




\begin{tabular}{cccc}
3 & Short Survey & 28 & 1.2 \\
4 & Note & 21 & 0.9 \\
5 & Conference Paper & 18 & 0.77 \\
6 & Book chapter & 4 & 0.17 \\
7 & Letter & 5 & 0.21 \\
\hline $8 .$. & Editorial & 1 & 0.04 \\
9 & Erratum & 1 & 0.04 \\
\hline
\end{tabular}

\subsubsection{AVERAGE KEYWORDS PER ARTICLE}

Table 6 reveals that 2333 papers had 712 keywords appended to them. The majority of researchers have access to the Article 712 key word (30.51\%). Nonhuman 655 comes in second place out of nine submissions (28.07\%). The typical keyword search (Animal Experiment 201 with 8.61\%) is at the very bottom of the research.

\begin{tabular}{|cccc}
\hline \multicolumn{5}{l}{ Table 6 Average Keyword per Article } & & \\
\hline Sl. No. & Key Words & Number of Documents & Percentage \\
\hline 1 & Article & 712 & 30.51 \\
\hline 2 & Nonhuman & 655 & 28.07 \\
\hline 3 & Controlled Study & 308 & 13.2 \\
\hline 4 & Animalia & 225 & 9.64 \\
\hline 5 & Female & 217 & 9.3 \\
6 & Animal Experiment & 201 & 8.61 \\
\hline 7 & Male & 184 & 7.88 \\
\hline 8 & Animals & 170 & 7.28 \\
\hline 9 & Animal Tissue & 144 & 6.17 \\
\hline 10 & Animal & 143 & 6.12 \\
\hline
\end{tabular}

\subsubsection{PREFERRED JOURNALS}

The Indian Veterinary Journal was the most popular journal among veterinarians, with 1280 submissions (54.86\%), followed by the Indian Journal of Animal Sciences with 369 papers (15.81\%). Three publications, Indian Journal of Animal Research 104 papers (4.45\%), Veterinary World 69 papers (2.95 percent), and Journal of Veterinary Parasitology 52 papers $(2.22 \%)$, are among the top five most popular Scopus journals, according to the survey. Table 7 shows the top ten most popular journals, together with the number of papers published in each.

Table 7 Rank-wise analysis of Veterinary Journals

\begin{tabular}{cccc}
\hline Sl. No. & Title of the Journal & Number of Documents & Percentage \\
\hline 1 & Indian Veterinary Journal & 1280 & 54.86 \\
\hline 2 & Indian Journal of Animal Sciences & 369 & 15.81 \\
\hline 3 & Indian Journal of Animal Research & 104 & 4.45 \\
\hline 4 & Veterinary world & 69 & 2.95 \\
\hline 5 & Journal of Veterinary Parasitology & 52 & 2.22 \\
\hline 6 & Tropical Animal Health and Production & 51 & 2.18 \\
\hline 7 & Buffalo Bulletin & 37 & 1.58 \\
\hline 8 & Veterinarski Arhiv & 33 & 1.41 \\
\hline 9 & Small Ruminant Research & 17 & 0.72 \\
\hline 10 & Veterinary Record & 16 & 0.68 \\
\hline
\end{tabular}




\subsubsection{DISTRIBUTION OF PUBLISHED DOCUMENTS IN SPONSOR RESEARCH}

Table 8 shows the distribution of research publications published in the Indian Council of Agricultural Research between 1986 and 2020. It contributed the most research articles, with an average of 29 research articles out of 2333 . Out of six significant institutes, the Department of Biotechnology, Ministry of Science and Technology, India comes in second with 18 papers (0.07\%), and the Biotechnology and Biological Sciences Research Council comes in third with 10 documents $(0.42 \%)$.

\begin{tabular}{|c|c|c|c|}
\hline $\begin{array}{l}\text { Sl. } \\
\text { No. }\end{array}$ & Name of the Institution & $\begin{array}{l}\text { Number of } \\
\text { Documents }\end{array}$ & Percentage \\
\hline 1 & Indian Council of Agricultural Research & 29 & 1.24 \\
\hline 2 & $\begin{array}{c}\text { Department of Biotechnology, Ministry of Science \& } \\
\text { Technology, India }\end{array}$ & 18 & 0.77 \\
\hline 3 & $\begin{array}{c}\text { Biotechnology \& Biological Sciences Research } \\
\text { Council }\end{array}$ & 10 & 0.42 \\
\hline 4 & $\begin{array}{c}\text { Department of Biotechnology, Government of West } \\
\text { Bengal }\end{array}$ & 8 & 0.34 \\
\hline 5 & $\begin{array}{c}\text { Guru Angad Dev Veterinary \& Animal Sciences } \\
\text { University }\end{array}$ & 6 & 0.25 \\
\hline 6 & $\begin{array}{l}\text { Department of Science \& Technology, Ministry of } \\
\text { Science and Technology, India }\end{array}$ & 5 & 0.21 \\
\hline
\end{tabular}

\subsubsection{RANK-WISE DISTRIBUTION OF THE COUNTRIES PUBLICATIONS}

According to the study, India is the leading country in veterinary research, contributing 2283 papers, and accounting for nearly (97.85\%) of global research output. The United States comes in second with 31 papers $(1.32 \%)$, the United Kingdom comes in third with 18 papers $(0.77 \%)$, and Australia comes in fourth with 9 papers $(0.38 \%)$. Table 9 lists the top ten countries based on the number of publications.

\begin{tabular}{|cccc|}
\hline \multicolumn{4}{|c}{ Table 9 Rank wise distribution of the countries publications } \\
\hline Sl. No. & Country & Number of Documents & Percentage \\
\hline 1 & India & 2283 & 97.85 \\
\hline 2 & United States & 31 & 1.32 \\
\hline 3 & United Kingdom & 18 & 0.77 \\
\hline 4 & Australia & 9 & 0.38 \\
\hline 5 & Canada & 9 & 0.38 \\
\hline 6 & Ethiopia & 5 & 0.21 \\
\hline 7 & Austria & 4 & 0.17 \\
\hline 8 & China & 4 & 0.17 \\
\hline 9 & Pakistan & 4 & 0.17 \\
\hline 10 & Thailand & 4 & 0.17 \\
\hline
\end{tabular}




\subsubsection{LANGUAGE DISTRIBUTION}

With 2305 papers (98.79\%), English is the most common language used by researchers for communication in Veterinary Research, followed by Croatian with 4 $(0.17 \%)$ and Italian with $1(0.04 \%)$. Table 10 lists the top three most commonly spoken languages.

\begin{tabular}{|cccc|}
\hline \multicolumn{2}{|c}{ Table $\mathbf{1 0}$} & Language & Distribution of Euphorbia hirta Analysis \\
\hline Sl. No. & Country & Number of Paper & Percentage \\
\hline 1 & English & 2305 & 98.79 \\
\hline 2 & Croatian & 4 & 0.17 \\
3 & Italian & 1 & 0.04 \\
\hline
\end{tabular}

\section{FINDINGS}

These are the findings of the Scientometric study and it is hoped this finding is likely to be helpful for the stakeholders of Scopus analysis knowledge managers in these areas:

The research's findings are listed below.

- The maximum number of papers will be published in 2011, while the fewest will be published in 1987.

- During the study period, the number of research publications provided by many authors was the highest.

- Balachandran $\mathrm{C}$ is the most highly ranked author in the Scopus analysis, with 204 publications (11.5\%), followed by Kumanan K with 123 papers $(6.95 \%)$.

- In terms of number of authors, 1-25 produced 105 numbers of authors who published articles between 1986 and 2020.

- $\quad$ Out of five years, there were 315 citations (13.65\%). The lowest number of citations was 104 in 2016 , with $4.51 \%$ of other authors.

- The study finds that journal articles, with 2205 papers (94.5\%), are the most common source of publications covered by Scopus database for the specialty of Veterinary Research, followed by reviews with 50 pieces $(2.14 \%)$.

- The majority of researchers have access to the Article 712 key word (30.51\%).

- The Indian Veterinary Journal was the most popular journal among veterinarians, with 1280 submissions (54.86\%), followed by the Indian Journal of Animal Sciences with 369 pieces (15.81\%).

- The distribution of research publications published in the Indian Council of Agricultural Research between 1986 and 2020. It contributed the most research articles, with an average of 29 research articles out of 2333.

- India is the leading country in veterinary research, contributing 2283 papers, and accounting for nearly (97.85\%) of global research output.

- With 2305 papers (98.79\%), English is the most common language used by researchers for communication in Veterinary Research, followed by Croatian with $4(0.17 \%)$ and Italian with $1(0.04 \%)$. 


\section{CONCLUSION}

The research output of Tamil Nadu Veterinary and Animal Sciences University was talented and exhibited a growing trend in recent years, according to the results of Scopus publication analysis in the discipline of Veterinary. The concepts of research areas have been strong and number of strength articles published in Scopus Database. There are also some interesting areas to be studied as the impact of particular papers on Veterinary disciplines analysis of the veterinary publications based on the chosen top managerial journals indexed in Scopus.

\section{REFERENCES}

Dalia El Khaled et al., (2018). Dielectric and Bio-impedance Research Studies: A Scientometric Approach Using the Scopus Database. MDPI Journal , Vol.6, 6. Retrieved from https://doi.org/10.3390/publications6010006

Hilary I Okagbue et al. (2020). Disparities in document indexation in two databases (Scopus and Web of Science) among six subject domains, and the impact on journal-based metrics. Scientometrics, Vol.125, pp.2821-2825. Retrieved from https://doi.org/10.1007/s11192-020-03704-1

Kot S and Grabara J (2017). Publications Analysis According to Management Disciplines Based on Scopus Indexed Journals from Easter European Countries. Polish Journal of Management Studies, Vol16(2), pp.147-159. Retrieved from https://doi.org/10.17512/pjms.2017.16.2.13

Mohammadamin Erfanmanesh (2017). The Publication Success of 102 Nations in Scopus and the Performance of Their Scopus-Indexed Journals. Publishing Research Quarterly, Vol.33, pp.421-432. Retrieved from https://doi.org/10.1007/s12109-017-9540-5

Mukherjee Bhaskar (2013). A Scientometric profile of Prof. Lalji singh as seen through Web of Science and Scopus. Annals of Library and Information Studies (ALIS), Vol.60(3).

Rajendran L (2021). Cab direct is the focus of a Scientometric analysis from 2011 to 2013: beans scientific research articles. International Journal of ResearchGRANTHAALAYAM, Vol..9(8). pp.35-41. Retrieved from https://doi.org/10.29121/granthaalayah.v9.i8.2021.4135

Rajendran L (2021). Wheat scientific research articles from 2011 to 2013: cab direct is the focus of a scientometric analysis. International Journal of Research and Analytical Reviews, Vol.8(3), pp.778-785.

Tripathi H.K and Garg K.C (2016). Scientometrics of Cereal crop Science Research in India as seen through SCOPUS database during 1965 - 2010. ALIS, Vol.6(3) pp.222-231.

Zoltan Krajcsak (2021). Researcher Performance in Scopus Articles (RPSA) as a New Scientometric Model of Scientific Output : Tested in Business Area of V4 Countries. MDPI Journal, Vol. 9, 50. Retrieved from https://doi.org/10.3390/publications9040050 


\begin{abstract}
About the Author
Dr. L. Rajendran is working as an Assistant Librarian in the Department of Library Science, Madras Veterinary College, TANUVAS, Chennai. He has completed a Master degree in M.K.University in 1993; he finished his M.Phil in 2003 from Alagappa University and Ph.D in 2008 from M.S.University. He has 23 years of experience in the field of Library and Information Science. He has published 116 research papers in different journals, conference and seminar proceedings and published 5 books in the field of library and information science. He has organised a number of training workshops, seminars and conferences in Library and Information Science. He is a life member of various International and National Associations. He has completed a World Bank funded research project "Strengthening of Digital Library and Information Management under NARS (e-Granth) and another project is "National Knowledge Management Centre for Agriculture Education and Research" funded under NAHEP. His research interests are Information Communication Technology (ICT), Digital Library, User Studies, Library Management, Scientometrics and Bibliometrics
\end{abstract}

